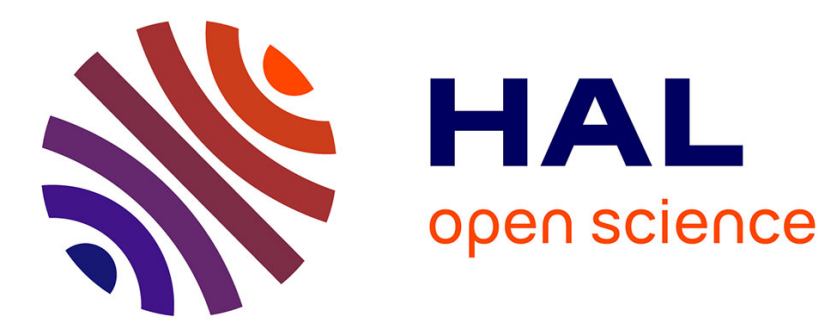

\title{
Spatial configuration in a periurban city. A cellular automata-based microeconomic model
}

Geoffrey Caruso, Dominique Peeters, Jean Cavailhès, Mark Rounsevell

\section{To cite this version:}

Geoffrey Caruso, Dominique Peeters, Jean Cavailhès, Mark Rounsevell. Spatial configuration in a periurban city. A cellular automata-based microeconomic model. Regional Science and Urban Economics, 2007, 37 (5), pp.542-567. 10.1016/j.regsciurbeco.2007.01.005 . hal-02663734

\section{HAL Id: hal-02663734 \\ https://hal.inrae.fr/hal-02663734}

Submitted on 31 May 2020

HAL is a multi-disciplinary open access archive for the deposit and dissemination of scientific research documents, whether they are published or not. The documents may come from teaching and research institutions in France or abroad, or from public or private research centers.
L'archive ouverte pluridisciplinaire HAL, est destinée au dépôt et à la diffusion de documents scientifiques de niveau recherche, publiés ou non, émanant des établissements d'enseignement et de recherche français ou étrangers, des laboratoires publics ou privés. 


\title{
Spatial configurations in a periurban city. A cellular automata-based microeconomic model
}

\author{
Caruso Geoffrey $^{a, b}$, Peeters Dominique ${ }^{a, c}$, Cavailhès Jean ${ }^{d}$, \\ Rounsevell Mark ${ }^{a}$
}

a) Department of Geography, Université catholique de Louvain, Louvain-la-Neuve, Belgium.

b) Fonds national de la recherche scientifique (FNRS), Brussels, Belgium

c) Center for operations research and econometrics (CORE), Université catholique de Louvain, Louvain-la-Neuve, Belgium

d) UMR CESAER, Institut national de recherche agronomique (INRA), Dijon, France

\begin{abstract}
This paper presents a microeconomic model of residential location that explores the emergence of a mixed belt where residents and farmers coexist beyond a city. The model is based on integrating urban economics with cellular automata in order to simulate equilibrium patterns in $2 \mathrm{D}$ and through time. Households commute to a CBD and enjoy neighbourhood externalities that are a function of both local residential density and farmland, or open space. They bid on the competitive land market and locate so as to maximize utility. Incremental population growth changes the neighbourhood and leads to rent adaptations. With appropriate parameter values a mixed belt may emerge between the urban and agricultural specialized areas. Settlements within this mixed area are more or less clustered or scattered depending on preferences and neighbourhood size.
\end{abstract}

Key words: urban sprawl, open space, neighbourhood externalities, cellular automata, residential dynamics

JEL classification: C61, C63, D62, R14, R21

Corresponding author: Geoffrey Caruso, 3, Place Pasteur, Louvain-la-Neuve, B-1348, Belgium. Tel. +32 104728 73, Fax. +32 104728 77. caruso@geog.ucl.ac.be 


\section{Introduction}

The diffusion of residents from cities into rural hinterlands is a major spatial change affecting many metropolitan areas. For several decades, urban expansion, or urban sprawl, has located residents either within rural areas in mixed housing-farming arrangements or in 'exburbs', far from the centres, in scattered urban developments. ${ }^{1}$ Burchfield et al. (2002) quote the US House of Representatives (1980) when saying that urban development is 'like Swiss cheese with more holes than cheese'. These trends have led to an increase in land use planning policy to conserve green spaces. In the US, according to the Trust for Public Land, 1,065 out of 1,376 conservation ballot measures were passed in 43 states between 1996 and 2004, raising over $\$ 27$ billion in funding for land conservation. For example, in the 4 November 2004 elections, voters in 120 communities of 26 states passed ballot measures to create $\$ 3.25$ billion to protect land as parks and open spaces. In some Western European countries, a longer tradition of spatial planning has aimed to preserve space from development. In England for example, the Green Belt policy guidance, dating back to the 1930s, sought to prevent urban sprawl by keeping land permanently open. About 1.5 million hectares of land (or 12 per cent of the territory) is protected in order to retain attractive landscapes and recreational opportunities ${ }^{2}$. The Dutch Compact City policy is a further typical example of a strategy that creates extensive green open spaces, even within very densely populated areas such as the Randstad, Holland with growth in total households.

It is necessary to further understand the economic processes of the emergence, at the periphery of cities, of urban spatial morphologies with large open spaces, easements protected farmland, leapfrogs, greenbelts, scattered expan-

\footnotetext{
${ }^{1}$ In this sense, these settlements differ from 'suburban areas', which are considered to be a contiguous, built-up extension of the city without emphasizing any mix of land uses or scattered urbanisation.

${ }^{2}$ Office of the Deputy Prime Minister, Planning Policy Guidance 2
} 
sion, etc. This is the objective of the work presented here.

Within the canonical monocentric framework, it is possible to introduce externalities, including local public goods and open spaces (or inversely, crowding) (Fujita, 1989). However this framework is rather limited for modelling heterogeneous or mixed space, or scattered development. Facing this challenge, attempts have been made to model the consumer's taste for open spaces in different ways. Some studies favour an empirical approach and attempt to measure the value of open space with econometric tools (e.g. hedonic pricing, contingent valuation). Others choose theoretical methods and try to model scattered urban patterns, agents' interactions and leapfrog development. The work presented here adopts the second approach with a model inspired by the seminal work of Ogawa and Fujita (1980); Fujita and Ogawa (1982). Here, local potentials arise between residents (households preference for neighbourhood interactions), and 'green' externalities arise from the proximity of farmers. This microeconomic model is combined with a cellular automaton that simulates neighbourhood interactions in two-dimensional space and through time. The model generates city with a central residential area and a mixed periurban belt that becomes denser nearer to the centre and as population grows, and a variety of mixed spatial structures, including scattered development that are stable over the long-term.

The article is organised as follows. The next section presents the state-ofthe-art about mixed forms and discontinuous urban development, and the use of cellular automata to analyse such settlement patterns. Subsequently, the economic model and its coupling with a cellular automaton is described as well as the long-run properties of this integrated model. Finally, the 2D simulation results are presented and discussed with some perspectives on future research. 


\section{State-of-the-art}

Numerous econometric studies have shown that open spaces, golf courses, public parks, green belts, forests and often agriculture are much sought-after living environments. These results explain the growth in analytical and theoretical approaches to modelling the preferences for open space, including the use of cellular automata. These three aspects: applied studies, analytical models and cellular automata, are discussed below.

\subsection{The value of open spaces : applied research}

Methods of revealed preferences (hedonic pricing or transport costs) and stated preferences (contingent valuation or conjoint analysis) have shown that households are willing to pay for open/green spaces. These results are now sufficiently well accepted that it is not necessary for this article to present a large body of literature on the subject. Instead, key empirical findings are emphasised below using examples.

First, note that open spaces are only valued when they are in close proximity to a residence. Close proximity can mean contiguous (Thorsnes, 2002; Hobden et al., 2004; Mooney and Eisgruber, 2001; Earnhart, 2006), or a few tens or hundreds of metres: $400 \mathrm{~m}$ for Geoghegan et al. (1997), $600 \mathrm{~m}$ for Tyrvainen and Miettinen (2000), $500 \mathrm{~m}$ for Bolitzer and Netusil (2000) and $100 \mathrm{~m}$ for Kestens et al. (2001). For example, Thorsnes (2002) showed that in the Grand Rapids region (Michigan) the land adjacent to a forest had a greater value (?) by between 19 and $35 \%$ than land further away, but without a premium for houses located on the other side of the road. Bolitzer and Netusil (2000) showed that the proximity of golf courses or public gardens increased property values, but that being too close (less than $30 \mathrm{~m}$ ) had negative influences (congestion, noise), 
which counterbalance the positive amenity effects. These results suggest that immediate neighbourhoods matter and that the effect of externalities is highly localised and often decays non-monotonically with distance (congestion).

Using information about the legal status of land, Irwin (2002) showed that available private land has a negative influence on the price of neighbouring houses. This effect was attributed to the risk of subsequent housing development. Conversely, the preservation of agricultural land through land use planning increased the value of adjacent properties. Because of anticipation of conversion, it is controversial to consider agriculture as an open space. Using conjoint analysis, Roe et al. (2004), showed a positive effect, but conversely Paterson and Boyle (2002) and Smith et al. (2002) found negative relationships.

Other studies, such as the analysis of green spaces by Cheshire and Sheppard (2002), introduce econometric results within public economy models. Using previously estimated parameters from the two stages of a hedonic model (Cheshire and Sheppard, 1995, 1998), they calculated household utility, equilibrium rents and the net and gross benefits of various land use policies. They conclude that the provision of public gardens and peripheral agricultural areas (containing new urban development) brings net benefits to households, but that the resulting rise in property prices leads to costs that exceed the benefits, and thus that the net effect on welfare is negative. Bates and Santerre (2001) also combined theory and econometrics within an urban economic model where public green space enters the utility function of the consumer. They inferred a demand function and an econometrically estimable equation and showed that national and local public green spaces are slightly substitutable, while privately owned space and local public open space are not. These last two analyses account for the mechanisms by which land rent governs the trade-off between private and 
public spaces (the latter being congestible ${ }^{3}$ and generating externalities that can entail market failures). However, the gain in terms of theory and structural econometric modelling is obtained at the expense of the spatial dimension such as distances and neighbourhood interactions (the importance of which were discussed above).

\subsection{Mixed residential-agricultural space: economic mod- els}

Urban economic models that generate mixed space with heterogeneous agents were initially developed to understand the location of workers and consumers or industrial or commercial companies within specialised or mixed zones. Ogawa and Fujita (1980); Fujita and Ogawa (1982) produced a set of such models. One of these models was developed using two dimensional space (Ogawa and Fujita, 1989). The key elements in these models, as re-developed by Fujita and Thisse (2002), were the interactions between agents and the decrease of these interactions with distance. The interactions can lead to the endogenous generation of CBD's or polycentric cities, a major issue for these authors.

Such models attempt to open (at least partly) certain black boxes by showing the role of proximity interactions in the development of urban forms. Research in this area is, however, rare (Anas and Kim, 1996; Anas and Xu, 1999; Page, 1999). A small, but increasing, number of similar models have also been applied to mixed agricultural and residential spaces, where local interactions are due to agricultural externalities that benefit households.

Cavailhès et al. (2004b) proposed a model of this type with an exogenous CBD and linear space, where households and farmers locate according to their bid-rent. The bid-rent of the households depends on commuting costs and the

\footnotetext{
${ }^{3}$ Lee and Fujita (1983) already undertook an analysis of impure landscape public goods
} 
amenities provided by farmers. The analytical solution gave the equilibrium level of the agricultural amenities obtained when the two bid-rents are equal. By reasoning (as did Fujita and Ogawa, 1982) in terms of the density of households and farmers at each location, Cavailhès et al. (2004b) obtained a continuous mixed space, i.e. without residential and agricultural patches of measurable thickness.

Other models show the importance of underpinning model development with a two dimensional (2D) framework. Wu and Plantinga (2003) introduced an open space amenity in a household utility function. This exogenously located amenity decreased with distance within a 2D space, which allowed an analysis of the effect of the size and form of green zones. If the amenity was not centred, two residential zones could exist, one around the $\mathrm{CBD}$, the other around the green zone. Wu and Plantinga (2003) therefore accounted for leapfrogging in city development, which was one of their objectives. Marshall (2004) offers another theoretical example, where municipalities are distributed across a 2D spatial grid. An optimal proportion of public open spaces is sought in each municipality knowing that it can be substituted with private land consumption and also overflows into neighbouring municipalities. Cavailhès et al. (2004a) use a model where households consume various urban and green amenities at locations that are ordered hierarchically using a exogenously chosen fractal form (a Sierpinski carpet).

A further theoretical model, developed by (Turner, 2005), shares some similarities with the work presented here. Turner worked within a one dimensional, discrete space (while we will use two dimensions) with fixed property lots (we will make the same assumption) and within which migrants arrive (i.e. an open city model). When a resident is surrounded by vacant space, he receives a utility 'bonus', $\delta$ (in our case this will depend on the neighbouring density of green 
space). Turner obtained both a specialised city and a scattered ring within which contiguous parcels alternate between being occupied or vacant.

Turner proposed several variants to this approach. In one case, migrants arrive sequentially through time. The dynamics is driven by the unbalanced property market of an open city that receives migrants sequentially. This means that for each time step at least two landowners are in competition. Let us detail the underlying economic mechanisms since they are similar to those in the model presented here. Turner assumed that the households within the city have infinite moving costs and that the landowners are myopic, patient, and cannot change their prices through time. Consider the parcel that is just beyond the urban limit (parcel $\mathrm{n}^{\circ} 1$ ). It is vacant since its residential bid rent is less than the agricultural bid rent. Since the next parcel out $\left(\mathrm{n}^{\circ} 2\right)$ is not however bordered by residential land, its residential bid is higher and it is developed. The bid of this developed parcel $\left(\mathrm{n}^{\circ} 2\right)$ is equal to the agricultural bid rent increased by the marginal increase in transport costs (unitary) because the parcel is in competition with the third one $\left(\mathrm{n}^{\circ} 3\right)$, which could offer the same bonus $\delta$ (thus $\mathrm{n}^{\circ} 2$ and $\mathrm{n}^{\circ} 3$ landowners are Bertrand-type competitors). Once parcel $\mathrm{n}^{\circ} 2$ becomes occupied parcel $\mathrm{n}^{\circ} 3$ remains vacant because it no longer has the $\delta$ advantage. In contrast, the fourth parcel $\left(\mathrm{n}^{\circ} 4\right)$ is developed, owing to the bonus from the vacant third cell $\left(\mathrm{n}^{\circ} 3\right)$. Subsequent parcels alternate between being occupied and vacant until $\delta$ no longer compensates for the additional commuting costs.

Finally, Irwin and Bockstael $(2002,2004)$ undertook another kind of analysis and applied a 2D model to exurban Maryland to predict the location of change under different scenarios. The authors modelled urban conversion decisions by owners of undeveloped land. The decision to develop a parcel at a given moment in time is made by comparing the net gains at that moment with those for developing at a subsequent period. Neighbourhood externalities are 
embedded within the calculation of the gains in the form of a 'repelling' effect among residential parcels. The authors recast this model of optimal timing of development in stochastic terms in order to estimate parameters from a database of observed land conversions. Probabilities of development are updated at each time step for each cell as the externalities are lagged in time and endogenous. In applications, the model makes use of detailed spatial information (GIS). Furthermore, time is treated in the model in a similar way to ours and, as will be shown below, to cellular automata.

This review of economic models shows that the need for models developed in two dimensional space is essential for several authors Cavailhès et al. (2004a); Marshall (2004); Wu and Plantinga (2003); Irwin and Bockstael (2002) as is the sequence of decisions through time (Turner, 2005; Irwin and Bockstael, 2002). We have also seen that empirical models have identified the effect of short distances and immediate neighbourhoods. These conclusions reinforce our choice of using a cellular automaton model to operate an economic model within two dimensional space and through time. We now briefly present the key characteristics of cellular automata models and related literature.

\subsection{Cellular automata and urban dynamics}

CA are discrete dynamic systems that consist of a regular grid of cells, each being in a state taken from a finite set. Time is discrete. At a given moment $t$, the state of each cell is determined by its own state and the state of its neighbouring cells at $t-1$ according to a transition rule, which may be deterministic or stochastic.

The early theoretical developments of Cellular automata (CA) came during the infancy of computer science and were attributed mostly to Von Neumann (1966) based on work on self-reproducing machines. A classic example devised in the 1970's of a CA is Conway's Game of Life. This model is based on a 2D 
grid for which each cell has two possible states (dead or alive) and where the 8 cells contiguous to a particular cell are used to update the value of the cell using a deterministic rule: a cell is born if it has exactly 3 alive neighbours, it stays alive if it has 2 or 3 alive neighbours, but otherwise dies out or remains dead. These transition rules are applied simultaneously to all cells of the grid and lead to a variety of spatial configurations (stable, cyclical, gliding,...) depending on the initial patterns.

CA are increasingly applied to the modelling of natural and human systems. To better capture real-life processes, they sometimes include stochastic updating of cells (as for Markov processes), various sizes and forms of neighbourhood, cell-specific constraints on their rules, or non-simultaneous updating of the cells. Overall, the strength of CA models is to emphasize the role of local, neighbourhood-type, interactions in shaping aggregate forms. They are particularly useful therefore for analysing processes where the close proximity of different agents is assumed to impact on the evolution of spatial structure over time.

Early cellular dynamic models of socio-economic systems and human interactions in space were not necessarily referred to as CA. Sakoda (1971) and Schelling $(1971,1978)$ developed segregation models where individuals of two groups were located on a grid. A version of Schelling's model was developed in the urban context by Miyao (1979) who found that, within the monocentric framework, mixed patterns could be locally stable if the neighbourhood externalities were weak relative to the elasticity of utility with respect to land consumption. More recently, Axelrod (1984) and Nowak and May (1992) aimed to understand social dynamics and relate CA to Game Theory. Indeed, the significance of neighourhood (Schelling-type) interactions is still very much emphasised in recent empirical or theoretical work on residential change and the 
internal social structure of cities (e.g. Durlauf, 2004; Galster et al., 2000; Ioannides, 2002). However, as shown earlier, few economic studies have considered this modelling structure to represent mixed agricultural-residential patterns. The nearest 1D example being Turner (2005), and 2D simulation being Irwin and Bockstael (2002). In the mean time, geographers have been using CA to model urban sprawl processes.

CA passed from abstract games to geographical models after the work of Tobler (1979) and Couclelis (1985)(see Batty et al., 1997). Within the last ten to fifteen years CA applications of urban and regional land use change have been prolific $^{4}$. The generalized and constrained CA of White and Engelen $(1993,1997)$ is one of the best known applications that is combined with a regional model in order to simulate micro-scale land use change. A shared characteristic of this approach with economic models is the decreasing interactions between agentcells with distance within the neighbourhood. The SLEUTH model (Clarke et al., 1997; Clarke and Gaydos, 1998; Silva and Clarke, 2002) has also been used to describe urban growth patterns in different cities worldwide.

Geographical CA applications can simulate changes in land use and the complex forms of cities, but most do not relate spatial processes to the economic decisions of agents. Yet, some cellular models can be found, in which spatial externalities are the bridge between CA and urban economics. Page (1999) developed a model where agents have either negative or positive preferences for agglomeration and for the average distance to other people. While some results match the results obtained by Beckmann (1976) with his dispersed city model, the model considers economic variables only indirectly. Webster and Wu (1999a,b, 2001) proposed a micro-economic model of externality bargaining between polluting firms and residents within a CA framework that may

\footnotetext{
${ }^{4}$ An overview of this field is presented in the special issues edited by Batty et al. (1997) and Benenson and Torrens (2004).
} 
lead to spatial segregation of firms and residents. Parker and Meretsky (2004) modelled conversion from agricultural to urban use within a profit maximizing framework with positive or negative neighbourhood externalities. A static equilibrium is obtained by allowing one on two cells to change state successively in a checkerboard manner.

Within the urban monocentric framework, urban growth models with durable housing (reviewed by Brueckner (2000)) are the most similar to dynamic cellular models, as the spatial structure is not adjusted instantaneously but exhibit history-dependence. Although they do not consider externalities, these models provide properties that differ from the standard Alonso-Muth-Mills model. Anas $(1976,1978)$ has analysed housing durability under myopic landownership in a model where population growth is accommodated at the periphery of the city. Others have developed models with irreversibility and perfect foresight (e.g. Mills, 1981; Fujita, 1982; Wheaton, 1982; Turnbull, 1988), and show how positive density and rent gradients can occur, how land development can take place from the outside inward, and how leapfrogged, mixed or scattered development patterns can arise as equilibrium configurations.

The benefits we see from coupling $\mathrm{CA}$ and urban economics is to enable complex 2D spatial forms to emerge through time because of proximity interactions. The possibility exists, therefore, to relate observable mixed or scattered urban forms to agent preferences.

\section{The model}

\subsection{Assumptions and functioning of the model}

Let space be an isotropic area with a given and point-wise central business district $(\mathrm{CBD})$ where all employment is located and radially accessible from 
any point. This space is a discrete grid and each cell is occupied either by a household or by a farmer. ${ }^{5}$ Mixed use is not allowed. The surface of each grid cell is taken as the unit of surface and corresponds to the size of a residential plot (thus fixed).

Households are all identical and composed of a single worker/consumer. They commute to the CBD, rent a fixed residential lot, and consume a composite good that accounts for all other expenses. They benefit from two types of externalities. The first externality is named 'social' and results from the presence of other households in the neighbourhood. The second is a 'green' amenity that is produced by neighbouring farmers, if any, as a by-product of the production of agricultural goods. The farmers sell their production at the CBD and, therefore, have a Thünen-type bid-rent. The bid-rent of a household depends on commuting costs and on the environment of its location. The later depends on the quantity of the two externalities found in its neighbourhood. The externalities diffuse in all directions, but are limited to a certain distance (i.e. proximity interactions).

Absentee landlords allocate land to the highest bidder within a competitive land market but development is irreversible. Moreover, rents are negotiated at each time step across the whole area: we model a rental land market and not an ownership land market.

Because of some exogenous event, households from the 'rest of the World' may migrate into the area at no cost if they can obtain a utility surplus (i.e. an open-city model). We consider the case where these migrations occur: the city grows around its $\mathrm{CBD}$, which is assumed to provide enough employment. It is further assumed that in-migration is sequential and, without loss of generality, that only one household arrives at each time step (a sufficiently small unit of

\footnotetext{
${ }^{5}$ Note that we use residential and developed as synonymous, and similarly for agricultural and undeveloped.
} 
time is thus chosen). We model the micro-economic functioning of this economy so that a short-run equilibrium is obtained at each time period. Short-run equilibria follow from one another until the point in time where utility in the area is the same as in the 'rest of the World'. At that time, immigration stops and the long-run equilibrium is reached.

The sequential arrival of households leads to a land market where, in each short-run residential equilibrium, there is a surplus of supply relative to demand. This kind of unbalanced land market was discussed in section (2.2) using Turner (2005)'s model (although here we can relax the myopia assumption because we assume a rental market). In fact, the new migrant chooses the location that maximizes his utility. Thus he locates in a cell according to the distance separating the cell and the CBD and the externalities that he observes at the moment of his migration. In general, there are several sites with the same utility (if only because of the symmetric characteristics of the grid). The owners of these sites are Bertrand-type competitors facing the monopsonistic new migrant. This drives the rent paid by the unique immigrant down to the agricultural bid. The paid rent being lower than his residential bid-rent, the new migrant pockets a utility surplus.

At each time step, the arrival of an immigrant changes the density around the residential site chosen, i.e. the social and green externalities in the cells that makeup its neighbourhood. Following these changes, the threat of moving by the households that settled earlier (i.e. the tenants) forces landowners to adapt rents so as to equalize the utility of all city residents. At all time steps, equilibrium rents are such that, whatever the cell they occupy, all households have the same utility level which is fixed by the last immigrant. ${ }^{6}$ Moreover, the

\footnotetext{
${ }^{6}$ Whether each tenant actually moves or obtains a new rent from the landowner is not important. Moreover, the intra step actions (a new migrant arrives, rents adjust, tenants move) are simultaneous. We do not consider the Walrasian tâtonnement process.
} 
conversion of a cell into residential use is assumed to be irreversible. ${ }^{7}$

Two consequences arise from this economic and spatio-temporal functioning of the model. First, as long as the utility surplus is positive, a new immigrant is attracted from the 'rest of the World' and will settle at the next time step. Second, the utility surplus tends to decrease from one time step to another because of increasing commuting costs as the city expands ('regional' trend) even if neighbourhood conditions for a cell can be improved by the last immigration('local' effect). Because utility is the same in each cell, it is equivalent to the newly developed site to be occupied by the new immigrant or by a local tenant who moves to that cell.

In comparison with Turner (2005), migrants in our model also arrive sequentially through time and put landowners in competition. However, our hypotheses in terms of agent behaviour are different: intra-urban mobility is allowed and a rental market is considered so that households, using the threat of moving, can renegotiate the rent at each time step. Household utility is thus equal throughout the city at each time period and rents vary from place to place (conversely to Turner's model, where the rent is constant at each occupied location of the mixed ring). Moreover, our reasoning is made within a 2D world (as in Irwin and Bockstael (2002)) with a green amenity that depends on neighbourhood density, and a distance-decay effect (rather than being fixed and constrained to contiguous cells as in Turner). This allows for the emergence of complex spatial forms.

In the next section, we formalize the behaviour of the farmers and households (3.2), then the functioning of the cellular automaton (the dynamic and market equilibria (3.3), and the geometry and externalities (3.4)) and finally characterize the long-run equilibrium based on the available analytical information

\footnotetext{
${ }^{7}$ High costs are assumed for re-conversion of residential parcels to agricultural use, which is a realistic assumption. To simplify the approach, we do not model construction costs.
} 
(3.5).

\subsection{Microeconomics}

Farmers produce an agricultural good (with land as the only input and constant returns to scale) and amenities that are a by-product of farming. The harvest is sold at the CBD market. Calling $b$ the unitary transport cost and $d$ the distance from the $\mathrm{CBD}$, the agricultural bid-rent, $\Phi$ is a linear Thünen type equation:

$$
\Phi=\Phi_{0}-b d
$$

Households , all identical, maximize a Cobb-Douglas utility function $U$ :

$$
U(Z, E, S)=Z E^{\beta} S^{\gamma}
$$

where $\beta, \gamma \geq 0$. Utility depends on a non spatial composite good $Z$ (chosen as the numéraire), a residential plot (chosen as the surface unity), and externalities that are of two types: Environmental Externalities, E, representing preferences for a scenic landscape, proximity to forest and pastures, greenness, open space... and Social Externalities, $S$, representing preferences for social services and contacts, schools, public transport, network services. ${ }^{8}$

Households commute to the CBD to work and to shop and earn a fixed income, $Y$, a part of which is allocated to commuting costs. Calling $a$ the unitary commuting cost, $d$ the distance from the CBD and $R$ the land rent, the budget constraint is therefore:

\footnotetext{
${ }^{8}$ We do not ignore that agriculture generates negative externalities (noise, smell, pesticides, ...) nor that high urban density generates congestion, crowding, air pollution... In both cases, we assume a positive net balance of amenities and nuisance.
} 


$$
Y=a d+Z+R
$$

The maximization of (2) under the constraint (3) leads to the following indirect utility function:

$$
V=(Y-a d-R) E^{\beta} S^{\gamma}
$$

The reservation bid-rent, i.e. the maximum rent that a resident is ready to pay for a location in order to reach the same utility level $\bar{U}$ as in the 'rest of the World' is:

$$
\Psi=Y-a d-\bar{U} E^{-\beta} S^{-\gamma}
$$

Absentee landowners allocate undeveloped land to the highest bidder.

\subsection{Dynamics}

At each time step $t$, a single immigrant enters the city from the 'rest of the World'9 and makes a location choice based on the spatial distribution of the externalities at $t-1$ and the distances from the CBD. He chooses an agricultural cell in order to maximize his utility at that time, $U^{t}$, whatever future changes. ${ }^{10}$

For migration from the 'rest of the World' to occur, a utility surplus is required, i.e. $U^{t}-\bar{U}=\Delta U^{t}>0$. This condition is met as long as the rent paid by the new migrant, $R^{t}$, is lower than its reservation bid, $\Psi(\bar{U})$ (given by 5 ).

More precisely, the rent paid by the new migrant always equals the agricultural rent. In fact, we have $R^{t}=\Phi$ because at a given time, two (or more) agricultural cells may provide the same maximum utility level $U^{t}$ to the immi-

\footnotetext{
${ }^{9}$ Without loss of generality, the unit of time is chosen to adjust the growth rate to one. ${ }^{10}$ Future population growth and future change in their neighbourhood are unimportant to households because they rent a residential plot rather than purchasing it.
} 
grant. If not, the difference between the best and the second best undeveloped cells can at least be overlooked. As explained before, the arrival of a new single resident puts several landowners in competition on the land market with excess supply for a single new demand. The cells that are not chosen by the new resident only provide the agricultural rent, $\Phi$, to the landowners. Thus, the landowners will compete $\grave{a} l a$ Bertrand and the new resident pay the agricultural rent. The corresponding utility $U^{t}$ is then derived from the indirect utility function (4):

$$
U^{t}=(Y-a d-\Phi) E^{\beta} S^{\gamma}>\bar{U}
$$

It is further assumed that at time $t$, local households can move without moving costs across developed sites in order to maximize their utility. A shortrun equilibrium is reached when they equalize their utility to the level of the last immigrant, wherever the location. Therefore, their short-run land bid $\Psi^{t}$ is given from (4) similarly as (5) but using $U^{t}$ given in (6) instead of $\bar{U}$ :

$$
\Psi^{t}=Y-a d-U^{t} E^{-\beta} S^{-\gamma}
$$

Development being irreversible, the landowners have to accept this bid: $R^{t}=$ $\Psi^{t}$. As usual in residential equilibrium models, it does not matter whether the tenants move or not. The threatof moving forces landowners to adapt rents.

Note that particular cases may occur where $\Psi^{t}$ may be inferior to $\Phi$ when the new migrant locates closely and degrades the environment. In this case $E^{-\beta} S^{-\gamma}$ in (7) may raise. If $U^{t}$ does not decrease enough, $\Psi^{t}$ may fall below the agricultural bid. Thus, in some cells and some periods of time, the residential rent may decrease below the agricultural bid $\Phi$. We assume that, in this situation, the owner of a cell do not delay urban development as in option 
value models (Capozza and Helsley, 1989, 1990) because, as we will see with simulations, the cell can be in agricultural use indefinitely. ${ }^{11}$ The landowner is thus supposed to accept the development of the cell a time $t$ as soon as a household chooses this cell and his bid is higher than the agricultural bid. The situations where the residential rent decreases below the agricultural bid are generally temporary because the neighbourhood effect (local effect) is often absorbed after a few steps by the trend decrease in $U^{t}$ (regional trend). As will be shown in the simulations, exceptions exist however where the difference remains up until the long-run equilibrium.

The long-run equilibrium is reached at $\bar{t}$ as soon as the level of utility within the city equals the level of utility in the 'rest of the World': $U^{\bar{t}}=\bar{U}$. Thus, for the last migrant, equation (5) entails:

$$
\Psi^{\bar{t}} \equiv \Psi(\bar{U})=Y-a d-\bar{U} E^{-\beta} S^{-\gamma}=\Phi=R
$$

All other city inhabitants receive the same utility wherever their location. Their bid-rent is also given by (8) and according to the local value of distance and externalities. At that time, no household has an incentive to move either within the city or from the 'rest of the World'.

\subsection{Space and externalities}

Now consider a grid with a finite number of cells and a dimensionless CBD located at the origin $(0,0)$. Locations are now characterised by their $i j$ Cartesian coordinates. The area is featureless (except for the CBD) and isotropic, and there are no exogenous amenities. Each cell $i j$ is characterized by the Euclidean distance from the $\mathrm{CBD}, d_{i j}$, that is the commuting distance (households) or

\footnotetext{
${ }^{11}$ It is beyond the scope of this article to model the choice of the landowner between two sequences of rents deriving from two states, one being irreversible (urban) and the other (agricultural) which might also be indefinite.
} 
the distance to the agricultural market (farmers). The cell size is constant and equals the fixed size of a residential plot. At time $t$, each cell $i j$ is characterized by the presence of one, and only one, type of agent: Household $(H)$ or Farmer $(F)$. The state of a cell is $C_{i j} \in\{H, F\}$.

We now define and formalize the neighbourhood externalities that enter the household utility function.

Green and social externalities. $E_{i j}$, the neighbourhood environmental externality, is assumed to decrease with increasing residential density. This process represents losses of greenness and closure of the landscape caused by the presence of additional residents in the neighbourhood. $E$ is therefore a local dispersion force. Conversely, $S_{i j}$, the neighbourhood social externality, increases with increasing residential density. Additional residents in the neighbourhood are assumed to provide more personal contacts as well as additional commodities and services. $S$ is therefore a local agglomeration force.

Three definitions are needed to formalize these externalities:

Neighbourhood. The level of externalities at a given location $i j$ is a function of the land use in a neighbourhood denoted $\mathcal{N}_{i j} .{ }^{12}$ Each cell $k l$ belonging to $\mathcal{N}_{i j}$ is characterized by the Euclidean distance $f_{k l}$ separating $i j$ and $k l$, called the focal distance. The extent of the neighbourhood, i.e the maximum focal distance within a neighbourhood $\left(f_{k l} \leq \widehat{f}\right)$, is fixed and exogenously given and denoted by $\widehat{f}$.

Distance-decay. The two neighbourhood externalities, denoted by $E_{i j}$ and $S_{i j}$, are assumed to depend on distance between $i j$ and $k l$ : a weight $w_{k l}$ is given to each cell in $\mathcal{N}_{i j}$, depending on the focal distance $f_{k l}$ and the spatial extent

\footnotetext{
${ }^{12}$ The cell $i j$ itself is not part of its own neighbourhood.
} 
of the neighbourhood, $\widehat{f}$. The following decreasing function is chosen so that $0<w_{k l} \leq 1$

$$
w_{k l}=1-\left(\frac{f_{k l}-1}{\widehat{f}}\right)^{\sigma}
$$

where $\sigma$ is a positive parameter. The same distance-decay relationship is used for both externalities in order to simplify the analyis.

Local potential. We can now define the local interaction potential depending on both the density and the distance decay:

$$
\rho_{i j}=\frac{\sum_{k l \in \mathcal{N}_{i j}} w_{k l} H_{k l}}{\sum_{k l \in \mathcal{N}_{i j}} w_{k l}}
$$

where $H_{k l}=1$ if $C_{k l}=H$, and 0 if $C_{k l}=F$.

It can also be called a weighted density.

Functional form of the externalities. $E_{i j}$ and $S_{i j}$ can now be defined as functions of $\rho_{i j}$. Both externalities are given in exponential form:

$$
E_{i j} \equiv E\left(\rho_{i j}\right)=e^{-\left(\rho_{i j}\right)^{\theta}} \quad S_{i j} \equiv S\left(\rho_{i j}\right)=e^{\left(\rho_{i j}\right)^{\phi}}
$$

where both $\theta$ and $\phi$ have positive values.

It is reasonable to think that the marginal effect of the externalities on utility decreases. $E(\rho)$ should therefore be a strictly convex function of the neighbourhood weighted density, while $S(\rho)$ should be concave. Given that $\rho$ ranges from 0 to 1 , this leads to the following restrictions on the parameters: $\theta \in] 0,1], \phi \in] 0,0.5] .^{13}$

\footnotetext{
${ }^{13}$ These conditions can be considered without loss of generality, whatever the value of $\beta$ and $\gamma$, as utility is ordinal, and any monotonic transformation of a given utility function represents the same preferences. Details of all conditions can be found in Caruso (2005) available on request.
} 
Monotonic functions were chosen, and thus, for example, we do not account for congestion or isolation. Nonmonotonic functions would increase the number of parameters and therefore the number of simulations needed to explore the results.

Total neighbourhood amenity. Define the total of the local externalities by $L_{i j}=E_{i j}^{\beta} S_{i j}^{\gamma}$, i.e.

$$
L_{i j}=e^{\left(\gamma \rho_{i j}^{\phi}-\beta \rho_{i j}^{\theta}\right)}
$$

The new migrant takes this total externality in $t-1$ as given and maximizes $U(Z, E, S)=Z E^{\beta} S^{\gamma}=Z L$ subject to the constraint (3) for choosing a location at time $t$, and does not consider the effect of his own decision on the other households.

Given this functional form, different configurations of the total amenity, $L_{i j}(\rho)$, are found when varying the preference of households for a 'green neighbourhood' $(\beta)$ or for 'social neighbourhood amenities' $(\gamma)$. The examples presented in Fig.1a show $L$ ( $y$-axis) according to $\rho$ (x-axis), depending on the $\beta$ and $\gamma$ values.

[Figure 1 about here.]

In the case of the upper curve $(\beta=0, \gamma=1)$, households are not sensitive to green externalities. The denser the neighbourhood, the greater the amenity. For the bottom curve, $(\beta=1, \gamma=0)$, households prefer null density neighbourhoods. For the three intermediate curves, households trade-off the two externalities. When density is low, the total amenity increases with density because of social needs. As density increases, the increase in amenity becomes less important because of the concave shape of $S(\rho)$ and because of the decrease 
in greenness $E(\rho)$. A maximum level for the externalities is achieved at a certain level of weighted density. Further increasing the weighted density leads to more social interactions, but the decrease in greenness becomes increasingly important and decreases the total benefit.

The existence of a maximum in (12), $L(\rho)$, is conditional on $\theta>\phi$. Denote $\rho^{*}$ the optimal weighted neighbourhood density:

$$
\rho^{*}=\left(\frac{\phi \gamma}{\theta \beta}\right)^{1 /(\theta-\phi)}
$$

$\theta \beta \geq \phi \gamma$ is needed as an additional condition to have $\rho^{*} \in[0,1]$.

With a low preference for greenness (low $\beta$ ), $\rho^{*}$ is high. In this case, even within a completely urbanised environment $(\rho=1)$ households have neighbourhood benefits higher than 1 . With more preference for open environments (higher $\beta$ ), the optimal neighbourhood weighted density $\rho^{*}$ is achieved more rapidly and the decrease in total externalities comes earlier. However, disbenefits $(L(\rho)<1)$ can only be generated when $\beta>\gamma$, i.e. when the taste for greenness is high. When $\beta=\gamma=1$, households are indifferent to a fully urbanised neighbourhood $(\rho=1)$ and a completely empty neighbourhood $(\rho=0)$, but prefer intermediate densities. Finally, decreasing $\theta$ accentuates the convexity of the open space amenity and gives more importance to very low densities. Similarly, decreasing $\phi$ accentuates the concavity of the social amenity and also gives more importance to very low densities. In both cases, the optimal local density would be lower. ${ }^{14}$

\footnotetext{
${ }^{14}$ No sensitivity to $\theta$ and $\phi$ is undertaken within the simulations presented here, the parameters are considered as given parameters of household perceptions. The limit values $\theta=1$ and $\phi=0.5$ have been used to keep $\rho^{*}$ sufficiently far from 0 and so better differentiate the cases as the possible $\rho$ values are discrete. A larger magnitude of $L$ would be obtained with lower $\phi$, but this would imply lower $\rho^{*}$. Also, the magnitude of $L$ is already affected by $\beta$ and $\gamma$.
} 


\subsection{Long-run equilibrium}

We can now link the dynamic microeconomic model to the cellular space to obtain long-run spatial equilibria and show that a mixed periurban belt may emerge from the land market equilibrium.

The capacity of a new resident to bid over a farmer depends on the commuting cost and on the quality of the neighbourhood. The latter varies from place to place with no a priori relationship to the commuting distance. Denote by $\widetilde{d}$ the boundary between urban and agricultural areas in the standard case of urban economics with no externalities. $\widetilde{d}$ is the solution to: $\left.\Psi\right|_{\beta=\gamma=0}=\Phi$. Its existence is conditional on $Y-\bar{U}>\Phi_{0}$ (i.e. the city exists if the residential bid-rent is higher than the agricultural bid at the CBD) and $a>b$ (i.e. the city ends only if the slope of the residential bid-rent is steeper than the agricultural bid-rent).

When households enjoy externalities higher than one, equation (5) entails:

$\left.\Psi(\widetilde{d})\right|_{E^{\beta} S^{\gamma}>1}>\left.\Psi(\widetilde{d})\right|_{\beta=\gamma=0}$. Therefore, the household's bid-rent increases and the specialized agricultural area is pushed away from the CBD by the area where residents benefit from the externalities. To find out what the land use pattern is within this particular area, simulations are required (see section 4). However, whether this area is mixed and what are its position and extent directly depend on the value of the parameters. We show this below and present it in the form of three propositions.

Location specific bid-rents. The long-run residential bid-rent can be formulated as a function of the local weighted density, $\rho_{i j}$ (from 5 and 11):

$$
\Psi_{i j}=Y-a d_{i j}-\bar{U} e^{\left(\beta \rho_{i j}^{\theta}-\gamma \rho_{i j}^{\phi}\right)}
$$

One can see that there is a set of residential bid-rent curves at a given dis- 
tance from the CBD, each corresponding to a possible neighbourhood weighted density. Fig.1b plots four bid-rents ( $y$-axis) according to the distance from the CBD ( $x$-axis), for the case where the preference for open space amenities is slightly larger than the preference for social amenities $(\beta=1.25, \gamma=1.00$; bold curve in Fig.1a).

The lower curve, denoted by $\left.\Psi\right|_{\rho=1}$, corresponds to a fully urbanised environment ( $\rho=1$, i.e. the right end $\mathrm{F}$ of Fig.1a. With such an environment, the household bid-rent intersects the bid-rent of the farmer $(\Phi)$ at $d_{u}$. This is the limit of the specialized city. The upper curve of the Fig.1b, denoted by $\left.\Psi\right|_{\rho^{*}}$ corresponds to the optimal weighted density, $\rho^{*}$ (point C on Fig.1a). Commuting distance is logically the longest for this value. $d_{c}$ is the intersection of the residential bid-rent $\left.\Psi\right|_{\rho^{*}}$ and the agricultural bid-rent $\Phi$. Beyond this point, the area is specialized with agriculture. Within the distances $d_{u}$ and $d_{c}$, according to the social and green amenities, the residential bid-rents range between these two extreme curves. All intermediate values can be taken. The intermediate curves all intersect the agricultural bid-rent and thus some sites will be developed (those above $\Phi$ ) while others will not (those below $\Phi$ ).

Between $d_{u}$ and $d_{c}$ on Fig.1b a mixed belt will develop in the sense that there will be both agricultural and residential cells. Denote by $m=d_{c}-d_{u}>0$ the width of this theoretical mixed belt that varies with $\beta$ and $\gamma$, as does its location from the CBD. Because of the uniqueness of the land use within each cell, the pattern within the mixed belt will show scattered residential developments that fragment the agricultural space.

Existence and limits of the mixed belt. The limits $\widetilde{d}$ (traditional city without externalities), $d_{u}$ (inner limit of the periurban belt) and $d_{c}$ (outer limit of the periurban belt, i.e. maximum commuting distance) are the solution to 
$\Phi=\Psi$ (Eq.1 and 14) for different values of $\rho$ (Eq.10) (still with $a>b$ and $\left.Y-\bar{U}>\Phi_{0}\right)$. We can then obtain $d_{c}$ and $d_{u}$ with respect to $\tilde{d}$, the traditional fringe, respectively as the solution to $\Phi=\left.\Psi\right|_{\rho=\rho^{*}}$ and to $\Phi=\left.\Psi\right|_{\rho=1}$ :

$$
\begin{aligned}
& d_{c}=\widetilde{d}+\frac{\bar{U}\left(L\left(\rho^{*}\right)-1\right)}{(a-b) L\left(\rho^{*}\right)} \\
& d_{u}=\widetilde{d}+\frac{\bar{U}(L(\rho=1)-1)}{(a-b) L(\rho=1)}
\end{aligned}
$$

With the above mentioned parametric conditions for a maximum of $L(\rho)$ in $\rho^{*}$, we have $L\left(\rho^{*}\right)>1$. Thus, from $(15), d_{c}>\widetilde{d}$. The commuting fringe is greater than the classic urban fringe. Moreover, under the same conditions, we also have $L\left(\rho^{*}\right)>L(\rho=1)$, which, from (15) and (16), entails $d_{c}>d_{u}$ and thus the existence of a mixed belt $(m>0)$.

At the limit case $\theta \beta=\phi \gamma$, we have $\rho^{*}=1$ (from 13), and thus $L\left(\rho^{*}\right)=L(\rho=$ 1). From (15) and (16) we then obtain $d_{u}=d_{c}>\widetilde{d}$, i.e. there is no longer a mixed belt $(m=0)$. This case is schematically represented in Fig.2b. The same thing occurs a fortiori when the preference for environmental amenities is even smaller $\theta \beta<\phi \gamma$ (from $\left(13, \rho^{*}>1\right)$ or cancelled $\beta=0(L(\rho)$ then increases continuously).

Proposition 1 When $\beta>0, \gamma>0, \theta>\phi$, and $\theta \beta \leq \phi \gamma$, a fully urbanised neighbourhood represents a positive externality. The traditional city is thus further expanded, but there is no mixed belt: $d_{c}=d_{u}>\widetilde{d}$. If $\theta \beta>\phi \gamma$, there is a mixed belt for which the upper limit is greater than the standard fringe: $d_{c}>d_{u}$ and $d_{c}>\tilde{d}$.

[Figure 2 about here.]

Three different situations can be identified when the mixed belt exists $(m>0)$ according to the position of the lower limit $d_{u}$ with respect to the traditional 
urban fringe. These situations are shown in Fig.2c,d,e. The position of the mixed belt depends on the ratio $\beta / \gamma$.

When $\beta<\gamma$, we have $L(\rho=1)>1$ from (12) and then $d_{c}>d_{u}>\widetilde{d}$ from (15) and (16). The mixed belt falls beyond the classic urban fringe. At the limit case $\beta=\gamma$, the preference for social and environmental amenities equilibrates and the mixed belt becomes appended to the traditional fringe: $d_{c}>d_{u}=\widetilde{d}$. With stronger preferences for environmental amenities, $\beta>\gamma$, (12) indicates that $L(\rho=1)<1$ : the full occupancy of a neighbourhood leads to disamenities. Then (15) and (16) show $d_{c}>\widetilde{d}>d_{u}$, i.e. the mixed belt overlaps the classic fringe and reduces therefore the size of the specialized urban core. An example of this case was used previously in Fig.1b: households with a strong preference for green neighbourhoods encounter negative externalities when the local weighted density is high. Their bid-rent can therefore fall under the classic bid-rent (curve $\mathrm{E}=\mathrm{A}$ on Fig.1b, $\mathrm{E}$ being the local density level $(0<\mathrm{E}<1)$ that solves $L(\rho)=1$, see the intersection of the bold curve in Fig.1a with $L(\rho)=1)$ ), and a farmer can outbid the resident at a distance $d_{i j}<\widetilde{d}$.

Moreover increasing $\beta$, with $\gamma$ constant, results in a larger mixed area. In fact, a marginal increase of $\beta$ generates a larger decrease in $L\left(\rho^{*}\right)$ than in $L(\rho=$ 1) (from 12 and 13). Therefore, from (16) and (15), one can see that the decrease in $d_{c}$ is smaller than the decrease in $d_{u}$. This is represented in Fig.2 by widening the mixed belt from row $c$ to row $e$.

Proposition 2 When $m>0$ and $\beta<\gamma$, the mixed belt expands beyond the standard urban fringe: $d_{c}>d_{u}>\widetilde{d}$. When $m>0$ and $\beta>\gamma$, the mixed belt overlaps the standard urban fringe: $d_{c}>\widetilde{d}>d_{u}$. Other parameters being constant, increasing $\beta$ leads to a larger mixed area $m$.

In the limit case where there is no preference for social amenities $(\gamma=0)$, there is a corner maximum in $L(\rho=0)=1$. Any increase from the null 
local density is a disamenity. In this case, the maximum commuting distance equalizes the standard fringe (as found from (15) with $L\left(\rho^{*}\right)=L(\rho=0)=1$ ) and the mixed belt is thus entirely included within the limit of the standard city: $d_{c}=\widetilde{d}>d_{u}$. This case is shown in Fig.2f. It is also interesting to note that when $\gamma=0$ or more generally $\beta>\gamma$, the specialized urban core can disappear as soon as $d_{u} \leq 0$, i.e. $\left.\Psi(d=0)\right|_{\rho=1} \leq \Phi(d=0)$. The city is therefore mixed from the CBD.

An important but rather counter-intuitive property of the model results from the discussion about the limits:

Proposition 3 The preference for local social interactions is a local centripetal force ( $\rho^{*}$ increases), but also a regional centrifugal force that pushes the specialized residential and agricultural areas away from the $C B D$ ( $d_{u}$ and $d_{c}$ increases). The preference for local open space amenities is a local centrifugal force $\left(\rho^{*}\right.$ decreases), but also a regional centripetal force, that brings the specialized residential and agricultural areas closer to the $C B D$ ( $d_{u}$ and $d_{c}$ decreases).

\section{Simulations}

The model is non-linear, 2D and the long-run equilibrium is constructed through time after a sequence of short-run equilibria. Therefore, simulation is needed to further describe the spatial pattern of the mixed zone. We first describe the simulation method and the short-run land market equilibrium (4.1). We then illustrate the growth path of the city using an example (4.2) and finally discuss some long-run archetypal cities, obtained by changing the preference parameters (4.3). 


\subsection{Short-run equilibrium simulation}

We choose a square grid with 2500 cells. At $t=0$, all of these cells are in agricultural use. The region is then filled-in by the arrival of one migrant per time step $t$. There are three necessary conditions for a cell $i j$ to be developed at time $t$ by the new immigrant: (i) the cell is in an agricultural state at $t-1$, (ii) the utility of the household at $i j$ is higher than in the 'rest of the World' (this is the incentive to migrate into the region, which cancels out in all cells at long-run equilibrium $\bar{t}$ ), and (iii) from all the available cells, ij provides the highest level of utility as evaluated from observing the city at $t-1$ and bidding the agricultural rent $\Phi .{ }^{15}$

During the growth of the city $(t<\bar{t})$, the level of utility that the immigrant expects from migrating at time $t$ in location $i j$, is based on $L_{i j}^{t} \equiv L\left(\rho_{i j}^{t-1}\right)$. The utility obtained at time $t$ can thus be re-formulated to include this lag. Similarly to (6) and using (12), we have

$$
U^{t}=\left(Y-a d_{i j}-\Phi_{i j}\right) L_{i j}=e^{\left(\gamma\left(\rho_{i j}^{t-1}\right)^{\phi}-\beta\left(\rho_{i j}^{t-1}\right)^{\theta}\right)}>\bar{U}
$$

with $\rho_{i j}^{t-1}$ being given by with $H_{k l}=H_{k l}^{t-1}$.

Therefore, as long as $t<\bar{t}$, the land rent for the undeveloped cells at $t-1$ is

$$
\forall i j \mid C_{i j}^{t-1}=F: \quad R_{i j}^{t}=\Phi_{i j}
$$

while the land rent for the set of cells that were in residential use at $t-1$ is:

$$
\forall i j \mid C_{i j}^{t-1}=H: \quad R_{i j}^{t}=\Psi_{i j}\left(U^{t}\right)=Y-a d_{i j}-U^{t} e^{\left(\beta\left(\rho_{i j}^{t}\right)^{\theta}-\gamma\left(\rho_{i j}^{t}\right)^{\phi}\right)}
$$

\footnotetext{
${ }^{15}$ In our grid, two or more locations at the same distance from the CBD and with the same neighbourhood density, can provide the highest utility level. With a single migrant, only one cell can be converted into urban use. To resolve this problem, a tie-breaker is applied arbitrarily using a random number. Whilst this random element makes small changes to individual locations, it does not affect the fundamental results of the model, but may change the orientation of the overall morphology.
} 
which includes potential changes in the neighbourhood due to the new migrant (i.e. density at $t$ is now taken).

\subsection{Trajectory of spatial equilibria and rents}

A simulation is first conducted for the case where the preference for green externalities is higher than for social amenities $(\beta=1.25, \gamma=1.00)$ in order to show the growth path of the city and the development of a mixed belt. As shown in Fig.1b, a total externality lower than $1(L(\rho)<1)$ is possible when the neighbourhood density is high. The neighbourhood used here comprises 28 cells $(\widehat{f}=3.00)$. Figures 3 and 4 show the north east quadrant of the grid (other quadrants being symmetrical). Figure 3 is a zoom on the very first time steps and the cells closer to the CBD. Figure 4 maps land use change up to the long-run equilibrium $\bar{t}$ and the distribution of rents.

The first resident chooses the bottom left corner where the commuting cost is null $\left(L(\rho)=1\right.$ for all cells). Its utility is $Y-\Phi_{00}=7.00>\bar{U} \cdot{ }^{16}$ The situation is different for subsequent migrants who can trade-off commuting cost with a better quality neighbourhood, given the presence of previous residents. For instance, the third resident benefits from social interactions with the first and second residents as well as green amenities, and therefore raises utility to 8.37. Utility then gradually declines with newcomers as commuting costs increase. It is clear from $t=5$ to $t=12$ (and subsequently) that the development does not follow the minimum transport cost path. Households tend to locate contiguously along a central axis so as to benefit for contact with previous households and green cells alongside. Other areas then develop as the transport costs increase leading to a striped urban development (see Fig.4), typically with urban stripes that are two to three cells wide separated by one or two green cells.

\footnotetext{
${ }^{16}$ Parameter values for the simulations are: $Y=10, \bar{U}=5, \Phi_{00}=3, a=0.15, b=0.00$.
} 
As time passes, the cells that were leapfrogged or left between two stripes become urbanised, gradually leading to greater compactness close to the CBD. The compact part of the settlement is thus generated step by step, while in the meantime, the mixed zone is pushed outward.

[Figure 3 about here.]

[Figure 4 about here.]

These dynamics are reflected in the evolution of the rent. The effect of increasing utility and neighbourhood change in the first steps entail sharp decreases in land rent values close to the CBD (Fig.4,i). Land rent then begins to rise gradually, following the increase in population and commuting costs and the downward adjustment in utility. For example, at $t=100$, utility is 6.00 and the land rent profile decreases with distance in a more classical way (Fig.4,j). Later, as a consequence of filling in the locations that were leapfrogged in previous steps close to the $\mathrm{CBD}$, the rent profile tends to become more concave (e.g. compare $t=300$ and $\bar{t}=451$ in Fig.4, $k$ and $l$ ).

As shown on figure (Fig.4,j), rents change through time as a result of both population growth and increasing neighbourhood density. Land rent increases with population because the fringe is pushed outward and commuting distance increases. A mixed belt is gradually created and within this belt rents vary from place to place. The gradual urbanisation of neighbourhoods within the belt affects the general decreasing shape of the rent profile through time.

With the parameter values used in this simulation, the sequence of rents for a cell can be described by three stages:

1. Agricultural rent until conversion;

2. Then, fall in the rent following neighbourhood change due to new migrants at the fringe. This step can be preceded by rent increases if local density is 
far below $\rho^{*}$ at the moment of conversion and thus small density increases can provide benefits;

3. - Rent continuously increases following total population growth and fall in utility in the absence of change in the neighbourhood as newcomers settle further away;

- or rent falls again as a neighbouring cell that was initially leapfrogged is developed and the neighbourhood degradation is not compensated for by utility decreases due to the higher commuting costs of the new migrant.

The trajectory of a single cell can stop at any of these stages, when the long-run equilibrium $\bar{t}$ is reached and population growth stops.

From $t=2$ until the end state, some cells remain below the level of the agricultural rent (Fig.4 third row, and outlined cells on second row maps). A few steps before the long-run equilibrium, there may not be sufficient time to compensate for the neighbourhood effect.

Clearly, no landowner would accept to develop the cells where $R_{i j}<\Phi_{i j}$ at $\bar{t}$ and thus from $\bar{t}$ to $t=\infty$, except if they do not know the moment $\bar{t}$ of the long run equilibrium. It is realistic to assume that landowners think that such a fall is temporary and expect that the unknown $\bar{t}$ is sufficiently distant from $t(\bar{t} \gg t)$ and that their rent will be higher than the agricultural rent from $t^{\prime}$ $\left(t<t^{\prime}<\bar{t}\right)$ to $\infty .^{17}$

\footnotetext{
${ }^{17}$ Remind that an alternative assumption, based on the work of Capozza and Helsley (1989, 1990), is that conversion irreversibility causes a delay in the optimal moment of conversion and an option value that is capitalised in the rent. In our case however, if landowners choose to delay urban development they would take the risk to see their land undeveloped forever.
} 


\subsection{Archetype cities}

To illustrate how varying the preferences leads to different spatial configurations, five pairs of preference parameters (the $\beta, \gamma$ pairs corresponding to Fig.1b and Fig.2) are used in the following discussion and sensitivity to neighbourhood size

$(\widehat{f})$ is also analysed. ${ }^{18}$

Different long-run morphologies are shown in Fig.5 and compared to the standard model with no externalities (tile $a$ ). We identify three archetypes, named 'Compact city', 'Mixed Periurban belt', and 'Dispersed City' and describe them below.

[Figure 5 about here.]

The Compact City is defined by a clear break between residential and agricultural cells. This always occurs if green externalities are not included in the model (tiles $b$ and $c$ is case where $\beta=0$ ) and when the preference for social amenities is so high that the optimal density $\rho^{*}$ is beyond 1 (the condition $\theta \beta>\phi \gamma$ is not respected, e.g. tile $c: \theta \beta=\phi \gamma)$. Comparing tiles $b$ and $c$ with the standard model (tile $a$ ), it is also evident that the Compact City is more extended and populated (see $\bar{t}$ ). The increase in commuting cost is compensated for by the consumption of the social externalities.

These results were obtained earlier (see Proposition 1 and Fig.2b). However, the simulation brings the more surprising feature that the Compact City is 'polygonal' and not circular, i.e. its fringe is flattened (compare tiles $a$ and $b$ ). The reason for this is the strong preference of households for social contacts. The flattening of the borders allows households at the fringe to benefit from more social interactions. Indeed $\rho$ is higher along the edge of a square than

\footnotetext{
${ }^{18}$ Complementary developments can be found in Caruso (2005), available on request.
} 
along the perimeter of a circle. ${ }^{19}$ This flattening of the city boundary is weaker when households also value open spaces ( $\beta$ increases, compare tiles $b$ and c). The envelope polygon then has more sides and gradually tends towards a circle as the relative importance of local agglomeration decreases.

The Mixed Periurban Belt arises with stronger preference for agricultural amenities (Fig.5, tiles $d$ and $e$ ). A mixed area emerges between the urban and agricultural specialized areas. Again we find the results obtained analytically (Proposition 2 and Fig.2d): when preferences are neutral $(\beta=\gamma)$, the extent of the compact urban core coincides with the standard urban fringe $\left(d_{u}=\widetilde{d}\right)$ (Fig.5 $d$ ); when the preference for green amenities increases further, the size of the mixed belt increases because of a reduction in the specialized urban core $\left(d_{u}\right)$ and a smaller decrease in the commuting limit $\left(d_{c}\right)($ Fig.5 $d)$.

The Dispersed City then arises when the relative preference for local greenness is even higher. Households do not accept a fully occupied neighbourhood, even at close distances from the $\mathrm{CBD}$, and the specialized urban area disappears. The city is completely mixed and less populated (Fig.5, tile $f$ ). As found earlier, its extent is limited to the standard urban fringe.

Mixed morphologies. What is new from the simulation is the spatial arrangement of residences and agriculture within the mixed areas. We have seen in the previous section how stripes are created stepwise and how green gaps are later filled in. We see here that the Dispersed City entails spotted or clustered type developments while the Mixed Periurban City shows stripes and isolated leapfrogged cells. It is also clear from tiles $e$ and $f$ that there is a variation of the morphology within a given mixed belt. At shorter distances from the CBD, the

\footnotetext{
${ }^{19}$ This result is independent of any border effects. The $360^{\circ}$ pattern would be obtained by symmetry.
} 
morphology exhibits a gradual transition towards compactness (thinner green spaces or larger residential clusters). Further away from the centre, leapfrogs and stripes are of a constant width although distance is increasing. This two parts structure is evident in tile $e$. Indeed, there is no reason for a household to leap beyond the size of its neighbourhood in order to find an optimal density. Although distance is increasing, it cannot be compensated for by a better spatial arrangement (at the fringe, local density is optimal $\left(\rho^{*}\right)$ ).

Finally, the size of stripes and clusters depends on household preferences (e.g. compare the width of stripes in tile $d$ and $e$ ). The level of space fragmentation within the mixed areas can be measured and is shown to increase with green preferences (Caruso, 2005).

Neighbourhood size. For a given set of preferences, the morphology is further determined by the spatial horizon of households. Varying neighbourhood size $(\widehat{f})$ does not impact on the density of the mixed belts, but impacts on the width of residential stripes and agricultural fragmentation. Some variations in the size of the neighbourhood for the case where $\beta=1.25$ and $\gamma=1.00$ are given in Fig.6. The fragmentation of space is lower for larger neighbourhood extents, the size of residential clusters and stripes being wider. Other experiments have also shown that when households are not sensitive to local agglomeration, but only to greenness, they still cluster when a large neighbourhood is considered (Caruso, 2005).

[Figure 6 about here.]

The following summarizes the findings in terms of morphology obtained from these simulations:

Proposition 4 With strong preferences for neighbourhood interactions between households, the circular shape of the city becomes polygonal. When households 
have greater preference for local open space, a mixed belt exists in the form of residential stripes or clusters. The morphology within this mixed belt is more compact towards the centre and exhibits invariant local patterns near to the fringe. Landscape fragmentation increases with the preference for local greenness and when households have smaller spatial horizons.

Additional simulations and measures in Caruso (2005) showed that the dispersion of residents in the mixed belt leads to an excess of aggregated commuting cost in comparison with a standard city of the same population (with no externalities). The rent, however, is also higher and the benefits of fragmentation exceed the costs: if the rent was redistributed to the city inhabitants, the welfare would be higher in a Mixed Periurban Belt city than in a standard city of identical population. This is certainly an element to consider when assessing the social and economic costs of actual sprawl morphologies. Furthermore, it was also shown that a decrease in the unit commuting cost leads to a larger mixed belt with a similar morphology. A Thünen agricultural rent $(b>0)$ has similar effects. Conversely, increasing the level of income favours the compact part of the city and pushes the mixed belt (of the same size and morphology) further away from the CBD.

\section{Conclusion}

This article has presented a microeconomic urban model of the growth of a city with social and green amenities embedded within a cellular automaton. The model simulates the emergence of different residential morphologies with discrete time steps within a $2 \mathrm{D}$ and discrete monocentric space. The dynamics of the system are generated by the sequential decisions of migrants who choose a location according to their observations at the previous time step (commuting 
distances and neighbourhood amenities). We show that the sequential migration process adds a surplus to the household reservation utility, which is the incentive to migrate from the rest of the World, until the long-run equilibrium is reached. Different spatial configurations were observed. The compactness/fragmentation of space changes according to the relative importance that agents attach to neighbourhood social externalities with respect to neighbourhood green externalities.

Results were obtained both from the characteristics of the long-run equilibrium and from simulations on a square grid. It was found that the presence of local agglomeration forces might compensate for commuting costs and, therefore, expand the size and population of the city. Local agglomeration forces also change the circular shape of the standard urban economics city into a polygon. When increasing the preference for neighbourhood open spaces, a mixed area with farmers and residents emerges at the periphery of a compact urban core. Fragmentation of space arises as an equilibrium configuration in the form of clustered and striped settlements, which are smaller when residents have greater preference for local open-space or a smaller spatial horizon. Fragmented cities are also less populated.

The succession of micro-morphologies with distance from the CBD was emphasized and shows how people self-organize when they trade-off two opposing neighbourhood externalities with commuting costs. In dynamic terms, the preference for low local densities generates leapfrogging residential growth. When agricultural gaps are later filled in, land rent in the neighbouring locations decreases. The general decline in the rent profile tends therefore to curve in mixed periurban areas.

Methodologically, the model has shown that it is possible to overcome the differences between spatially-explicit simulations of land use change and the- 
oretical urban economics models. The model has provided insight into the relationship between residential preferences and spatial fragmentation. Future research could therefore address sprawl and sustainability issues, not only on the basis of aggregate economic indicators, but also on the basis of an evaluation of city forms.

Several models have recently been proposed in the literature to account for the development of urban forms characterized by irregularities and discontinuities and by mixed land uses. This diversity of models calls for a comparison of their assumptions, functioning and results, but also for a comparison of their results with reality. This can be achieved by calibrating econometric models derived from these theoretical models or by simulation with realistic parameter values. In this context applying our model in different areas is an important challenge. We think that the two-dimensional output of the model and the set of realistic assumptions that are made are an advantage in this respect. The ability of the model to generate spatial forms that compare with the observed pattern has already been assessed in the Brussels periurban area using different spatial indices(Caruso et al., 2005). Further research is to be conducted in order to set up precise calibration methods and derive behavioural parameters from matching the patterns generated by the model and the observed urban forms and evolutions.

We have brought microeconomic foundations into urban cellular automata and 2D space into an urban economic model. Our approach reinforces the link between urban economic theory and the 2D spatial structures and forms of urban change. Jointly with the availability of large scale spatial data, many applications are thus possible to further understand how the behaviour of economic agents generate specific urban forms. In fine, further developments from our method can, for example, be useful to inform planning authorities about 
how urban expansion should be controlled to face both market and coordination failures. More generally, analyses that combine both microeconomics and the generation of detailled urban forms may be useful for assessing the implications of urban sprawl processes as well as alternative land use planning options in terms of social costs, agents preferences, congestion, and environmental impacts.

Acknowlegdements: The authors are grateful to the editor, Professor R. Arnott, and an anonymous referee for very helpful comments and suggestions.

\section{References}

Anas, A., 1976. Short-run dynamics in the spatial housing market. In: Papageorgiou, G. J. (Ed.), Mathematical Land Use Theory. Lexington Books, Lexington Mass, pp. 261-275.

Anas, A., 1978. Dynamics of urban residential growth. Journal of Urban Economics 5, 66-87.

Anas, A., Kim, I., 1996. General equilibrium models of polycentric urban land use with endogenous congestion and job agglomeration. Journal of Urban Economics 40 (2), 232-256.

Anas, A., Xu, R., 1999. Congestion, land use and job dispersion. Journal of Urban Economics 45, 451-473.

Axelrod, R., 1984. The evolution of cooperation. Basic Books, New York.

Bates, L. J., Santerre, R. E., 2001. The public demand of open space : the case of Connecticut communities. Journal of Urban Economics 50, 97-111.

Batty, M., Couclelis, H., Eichen, M., 1997. Urban systems as cellular automata. Environment and Planning B 24, 159-164. 
Beckmann, M. J., 1976. Spatial equilibrium in the dispersed city. In: Papageorgiou, G. J. (Ed.), Mathematical Land Use Theory. Lexington Books, Lexington Mass, pp. 117-126.

Benenson, I., Torrens, P. M., 2004. Geosimulation:object-based modelling of urban phenomena. Computers, Environment and Urban Systems 28 (1-2), $1-8$.

Bolitzer, B., Netusil, N. R., 2000. The impact of open spaces on property values in Portland, Oregon. Journal of Environmental Management 59, 185-193.

Brueckner, J. K., 2000. Urban growth models with durable housing: An overview. In: Thisse, J. F., Huriot, J. M. (Eds.), Economics of cities : theoretical perspectives. Cambridge University Press, Cambridge, pp. 263-289.

Burchfield, M., Overman, H. G., Puga, D., Turner, M. A., 2002. The determinants of urban sprawl: A portrait from space. Working Paper.

Capozza, D. R., Helsley, R. W., 1989. The fundamentals of land prices and urban growth. Journal of Urban Economics 26, 295-306.

Capozza, D. R., Helsley, R. W., 1990. The stochastic city. Journal of Urban Economics 28, 187-203.

Caruso, G., 2005. Integrating urban economics and cellular automata to model periurbanisation: Spatial dynamics of residential choice in the presence of neighbourhood externalities. Doctoral thesis, Department of Geography, Faculty of Sciences, Universite catholique de Louvain.

Caruso, G., Rounsevell, M., Cojocaru, G., 2005. Exploring a spatio-dynamic neighbourhood model of residential dynamics in the Brussels periurban area. International Journal of Geographical Information Science 19 (2), 103-123. 
Cavailhès, J., Frankhauser, P., Peeters, D., Thomas, I., 2004a. Where Alonso meets Sierpinski: an urban economic model of a fractal metropolitan area. Environment and Planning A 36, 1471-1498.

Cavailhès, J., Peeters, D., Sekeris, E., Thisse, J. F., 2004b. The periurban city. why to live between the city and the countryside. Regional Science and Urban Economics 34 (6), 681-703.

Cheshire, P., Sheppard, S., 1995. On the price of land and the value of amenities. Economica 62 (246), 247-267.

Cheshire, P., Sheppard, S., 1998. Estimating the demand for housing, land, and neighbourhood characteristics. Oxford Bulletin of Economics and Statistics $60(3), 353-382$.

Cheshire, P., Sheppard, S., 2002. The welfare economics of land use planning. Journal of Urban Economics 52, 242-269.

Clarke, K. C., Gaydos, L. J., 1998. Loose-coupling a cellular automaton model and GIS: long-term urban growth prediction for san francisco and washington/baltimore. International Journal of Geographical Information Science 12, $699-714$.

Clarke, K. C., Hoppen, S., Gaydos, L., 1997. A self-modifying cellular automaton model of historical urbanization in the san francisco bay area. Environment and Planning B 24, 247-261.

Couclelis, H., 1985. Cellular worlds : a framework for modelling micro-macro dynamics. Environment and Planning A 17, 585-596.

Durlauf, S. N., 2004. Neighborhood effects. In: Henderson, V., Thisse, J.-F. (Eds.), Handbook of Urban and Regional Economics. Vol. 4. Elsevier, Amsterdam. 
Earnhart, D., 2006. Using contingent pricing space and its duration analysis to value open space at residential locations. Land Economics 82 (1), 17-35.

Fujita, M., 1982. Spatial patterns of residential development. Journal of Urban Economics 12, 22-52.

Fujita, M., 1989. Urban Economic Theory: land use and city size. Cambridge University Press, Cambridge.

Fujita, M., Ogawa, H., 1982. Multiple equilibria and structural transition on non-moncentric uban configurations. Regional Science and Urban Economics $12,161-196$.

Fujita, M., Thisse, J. F., 2002. Economics of Agglomeration: Cities, Industrial Location and Regional Growth. Cambridg University Press, Cambridge.

Galster, G. C., Quercia, R. G., Cortes, A., 2000. Identifying neighborhood thresholds: an empirical exploration. Housing Policy Debate 11 (3), 701-732.

Geoghegan, J., Wainger, L., Bockstael, N., 1997. Spatial landscape indices in a hedonic framework: an ecological economics analysis using GIS. Ecological Economics 23, 251-264.

Hobden, D., Laughton, G. E., Morgan, K., 2004. Green space borders - a tangible benefit? evidence from four neighbourhoods in Surrey, British Columbia, 1980-2001. Landscape and Urban Planning 21, 129-138.

Ioannides, Y. M., 2002. Residential neighbourhood effects. Regional Science and Urban Economics 32, 145-165.

Irwin, E. G., 2002. The effects of open space on residential property values. Land Economics 78 (4), 465-480. 
Irwin, E. G., Bockstael, N. E., 2002. Interacting agents, spatial externalities, and the evolution of residential land use pattern. Journal of Economic Geography $1,31-54$

Irwin, E. G., Bockstael, N. E., 2004. Land use externalities, open space preservation, and urban sprawl. Regional Science and Urban Economics 34, 705-725.

Kestens, Y., Thériault, M., des Rosiers, F., 2001. The impact of surrounding land use and vegetation on single-family house prices. Environment and Planning B 31, 539-567.

Lee, C. M., Fujita, M., 1983. Efficient configuration of a greenbelt: theoretical modelling of greenbelt amenity. Environment and Planning A 29, 1999-2017.

Marshall, E., 2004. Open-space amenities, interacting agents, and aquilibrium landscape structure. Land Economics 80 (2), 272-293.

Mills, D. E., 1981. Growth, speculation and sprawl in a monocentric city. Journal of Urban Economics 10, 201-226.

Miyao, T., 1979. Dynamic instability of a mixed city in the presence of neighborhood externalities. American Economic Review 68 (3), 454-463.

Mooney, S., Eisgruber, L. M., 2001. The influence of riparian protection measures on residential property values: the case of the oregon plan for salmon and watersheds. Journal of Real Estate Finance and Economics 22 (2-3), 273286.

Nowak, M. A., May, R. M., 1992. Evolutionary games and spatial chaos. Nature $359,826-829$.

Ogawa, H., Fujita, M., 1980. Equilibrium land use patterns in a non-monocentric city. Journal of Regional Science 20 (4), 455-475. 
Ogawa, H., Fujita, M., 1989. Nonmonocentric urban configurations in twodimensional space. Environment and Planning A 21, 363-374.

Page, S. E., 1999. On the emergence of cities. Journal of Urban Economics 45, $184-208$

Parker, D. C., Meretsky, V., 2004. Measuring pattern outcomes an agent-based model of edge-effect externalities using spatial metrics. Agriculture, Ecosystems and Environment 101 (2-3), 233-250.

Paterson, R. W., Boyle, K. J., 2002. Out of sight, out of mind? using gis to incorporate visibility in hedonic property value models. Land Economics $78(3), 417-425$.

Roe, B., Irwin, E. G., Morrow-Jones, H. A., 2004. The effects of farmland, farmland preservation, and other neighborhood amenities on housing values and residential growth. Land Economics 80 (1), 55-75.

Sakoda, J. M., 1971. The checkerboard model of social interaction. Journal of Mathematical Sociology 1, 119-132.

Schelling, T., 1971. Models of segregation. Journal of Mathematical Sociology $1,143-186$.

Schelling, T. C., 1978. Micromotives and macrobehavior. WW Norton and Company, New York.

Silva, E. A., Clarke, K. C., 2002. Calibration of the sleuth urban growth model for lisbon and porto, portugal. Computers, Environment and Urban Systems $26,525-552$.

Smith, V. K., Poulos, C., Kim, H., 2002. Treating open space as an urban amenity. Resource and Energy Economics 24, 107-109. 
Thorsnes, P., 2002. The value of suburban forest preserve: estimates from sales of vacant residential building lots. Land Economics 78 (3), 426-441.

Tobler, W., 1979. Cellular geography. In: Gale, S Olsson, G. (Ed.), Philosophy in geography. Vol. 9. Reidel, Dordrecht, pp. 379-386.

Turnbull, G. K., 1988. Residential development in an open city. Regional Science and Urban Economics 18, 307-320.

Turner, M. A., 2005. Landscape preferences and patterns of residential. Journal of Urban Economics 57, 19-54.

Tyrvainen, L. A., Miettinen, A., 2000. Property prices and urban forest amenities. Journal of Environmental Economics and Management 39, 205-223.

Von Neumann, J., 1966. Theory of self-reproducing automata. University of Illinois Press, Urbana, IL, (edited and completed by A. W. Burks).

Webster, C. J., Wu, F., 1999a. Regulation, land-use mix, and urban performance - part 1: theory. Environment and Planning A 31, 1433-1442.

Webster, C. J., Wu, F., 1999b. Regulation, land-use mix, and urban performance - part 2: Simulation. Environment and Planning A 31, 1443-.

Webster, C. J., Wu, F., 2001. Coase, spatial pricing and self-organising cities. Urban Studies 11, 2037-2054.

Wheaton, W. C., 1982. Urban residential growth under perfect foresight. Journal of Urban Economics 12, 1-21.

White, R., Engelen, G., 1993. Cellular automata and fractal urban form: a cellular modelling approach to the evolution of urban land-use patterns. Environment and Planning A 25, 1175-1199. 
White, R., Engelen, G., 1997. Cellular automata as the basis of integrated dynamic regional modelling. Environment and Planning B 24, 235-246.

Wu, J., Plantinga, A. J., 2003. The influence of public open space on urban spatial structure. Journal of Environmental Economics and Management 46 (2), 288-309. 


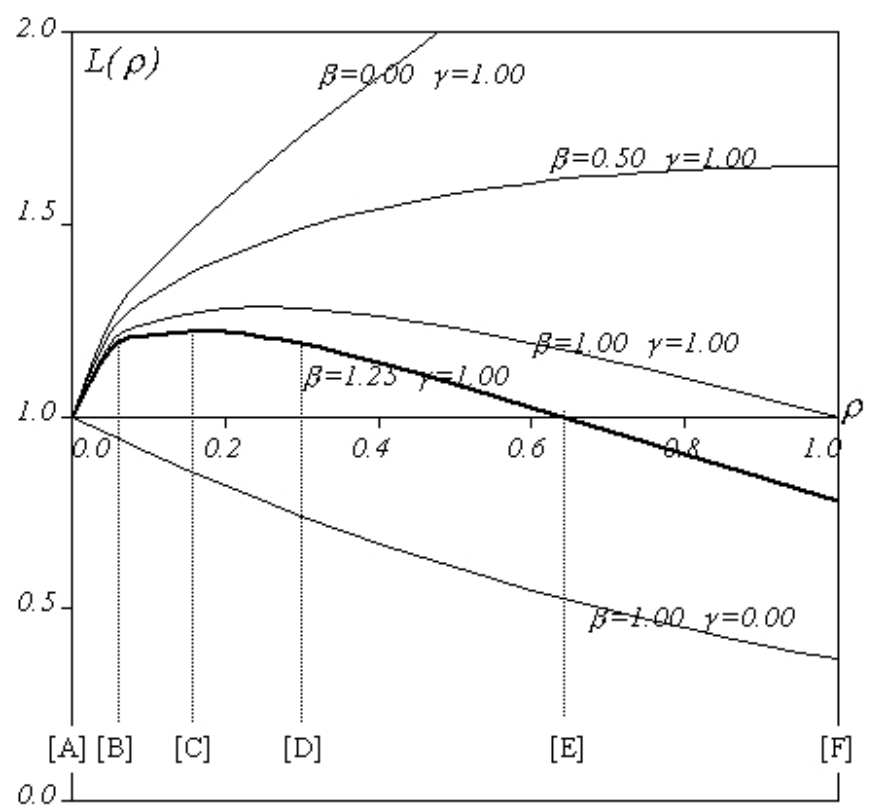

(a) Total externalities $L$ as a function of neighbourhood density $\rho$.

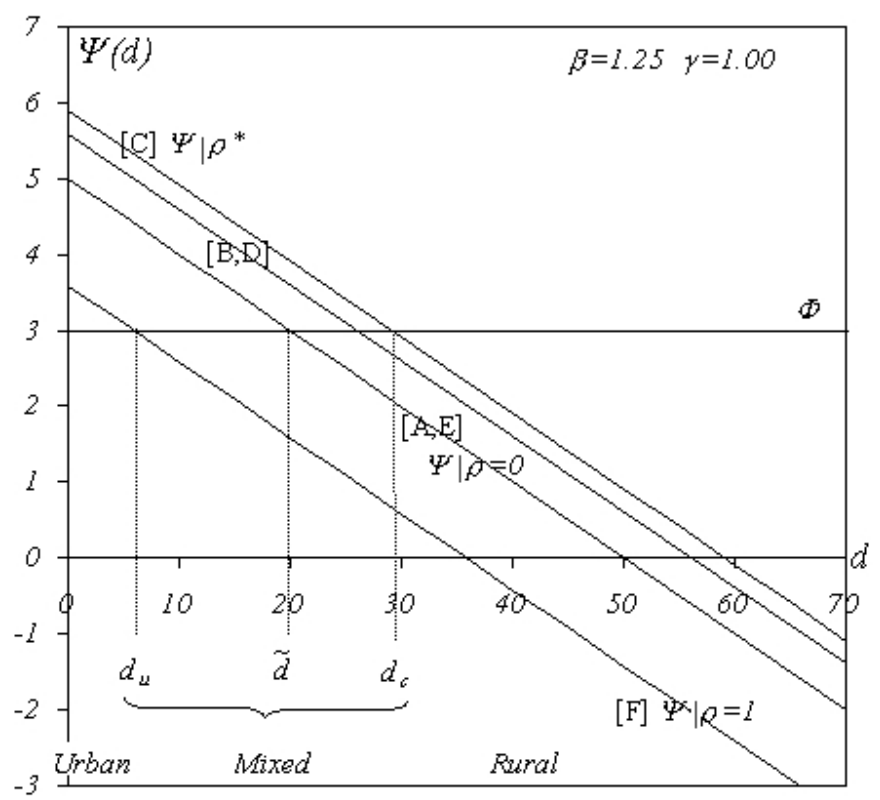

(b) Bid rents (with $\beta=1.25, \gamma=1.00$, i.e. bold curve in above figure).

Figure 1: Top: $L(\rho)$ with $\theta=1.0, \phi=0.5$ and five sets of preferences $(\beta, \gamma)$. Bottom: $\Psi(d)$ when $\beta=1.25, \gamma=1.00$ and $\theta=1.0, \phi=0.5$ (Slope of agricultural rent $(\Phi): b=0)$. $[\mathrm{A}]$ to $[\mathrm{F}]$ are particular values of $\rho$. $[\mathrm{A}]: \rho=0 ;[\mathrm{B}]$ : $\rho^{*}>\rho>0 ;[\mathrm{C}]: \rho=\rho^{*} ;[\mathrm{D}]: \rho>\rho^{*}$ such that $L(\rho)>1 ;[\mathrm{E}]: \rho>\rho^{*}$ such that $L(\rho)=1,[\mathrm{~F}]: \rho=1$. 


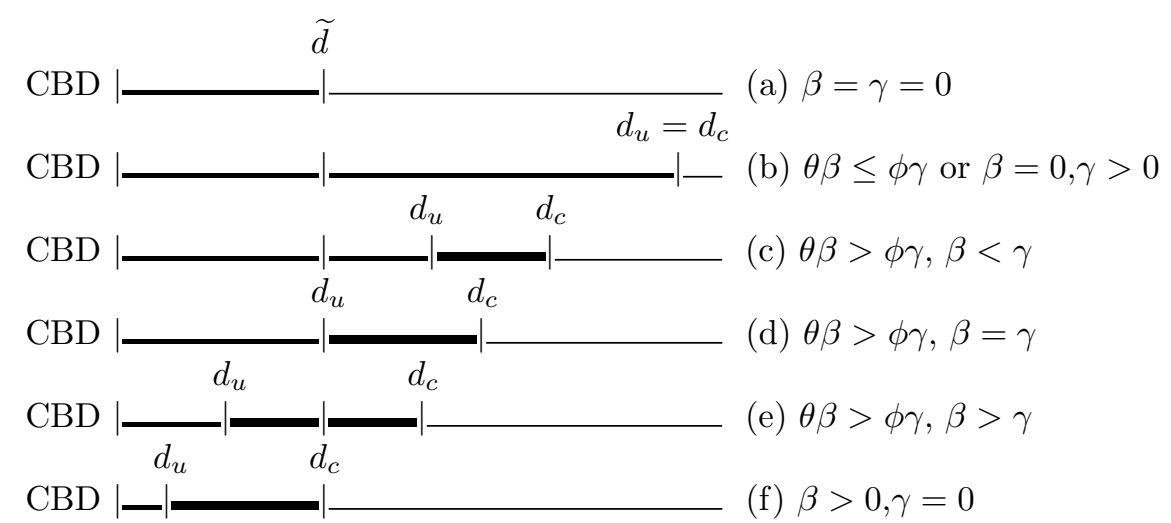

Figure 2: Urban boundaries. Position of the mixed belt with respect to the standard fringe when varying preferences (bold line: specialized urban area, bolder line: mixed area, light line: specialized rural area). 


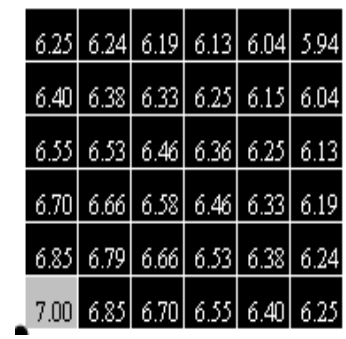

(a) $\mathrm{t}=1$

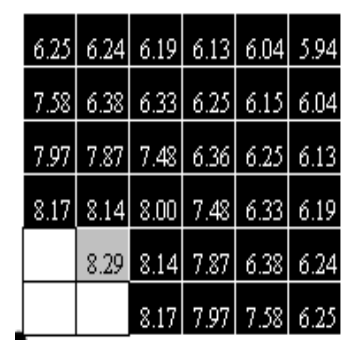

(d) $t=4$

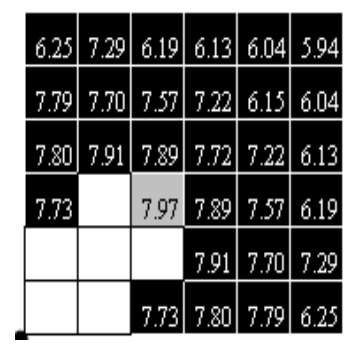

(g) $\mathrm{t}=7$

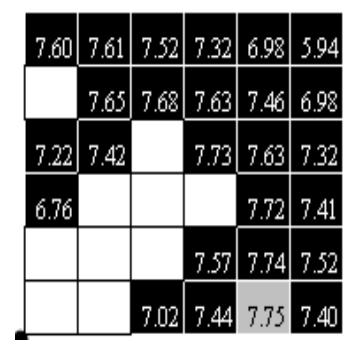

(j) $\mathrm{t}=10$

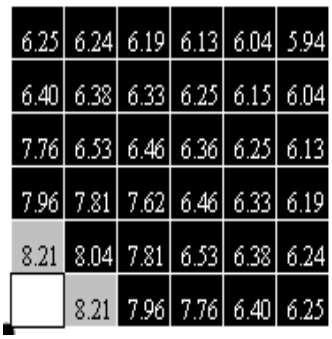

(b) $\mathrm{t}=2$



(e) $\mathrm{t}=5$

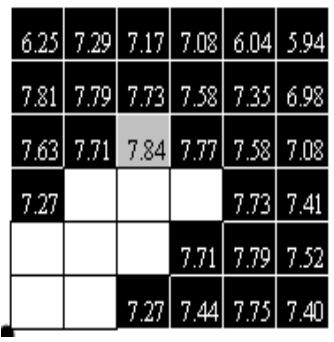

(h) $\mathrm{t}=8$

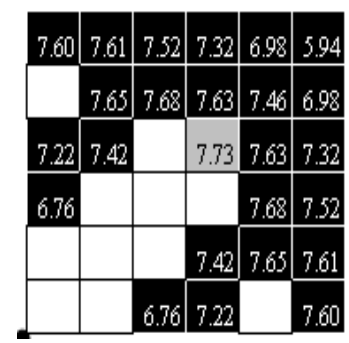

(k) $\mathrm{t}=11$

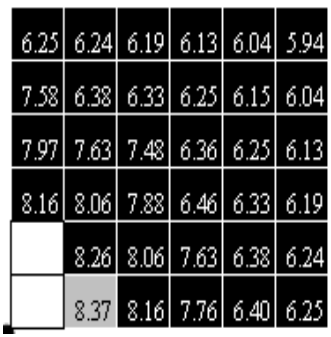

(c) $\mathrm{t}=3$

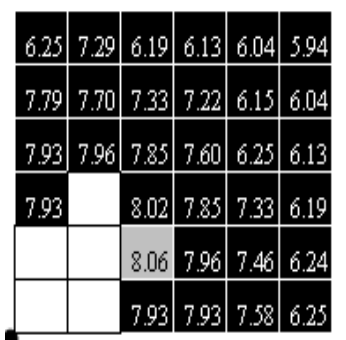

(f) $\mathrm{t}=6$

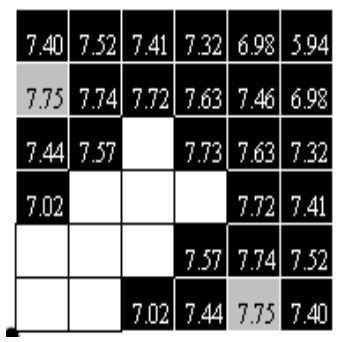

(i) $\mathrm{t}=9$

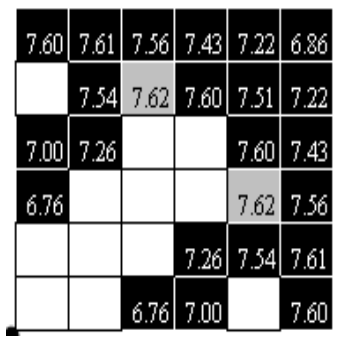

(l) $\mathrm{t}=12$

Figure 3: First iterations. 12 first time steps with $\beta=1.25, \gamma=1.00$, and $\widehat{f}=3.00$. Zoom on the 36 cells closer to the CBD. Utility ( $U^{t}$, i.e. immigrant paying $\phi$ ) is indicated within cells. Utility is maximum in grey cell(s). Black cells are agricultural. White cells are urbanised. 


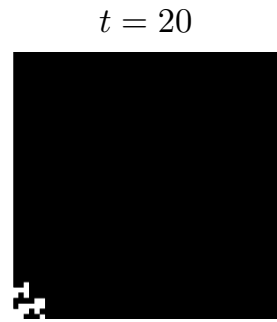

(a)

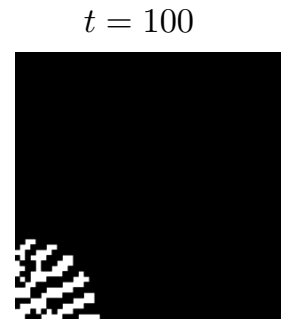

(b)

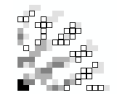

(f)

(e)

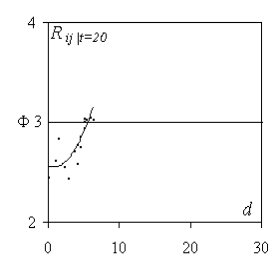

(i)

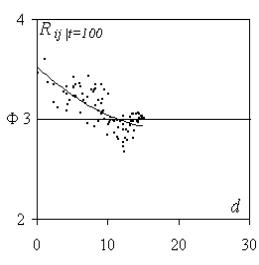

(j)

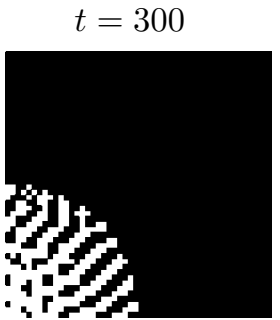

(c)

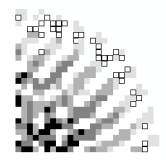

(g)

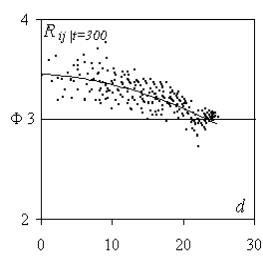

(k)

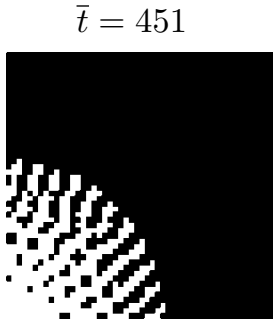

(d)

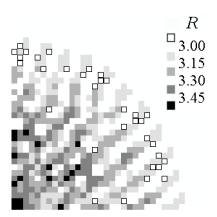

(h)

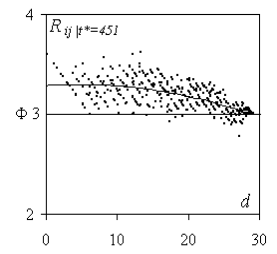

(1)

Figure 4: Short-run equilibria with $\beta=1.25, \gamma=1.00$, and $\widehat{f}=3.00 . \quad a$ to $d$ : land use (continued from Fig.3). $e$ to $h$ : Rent map (darker grey for higher rents, white boxed cells for $\mathrm{R}<\Phi=3.00$ ). Rent profile $R(d)$ (the curve is a 2nd order fit). 

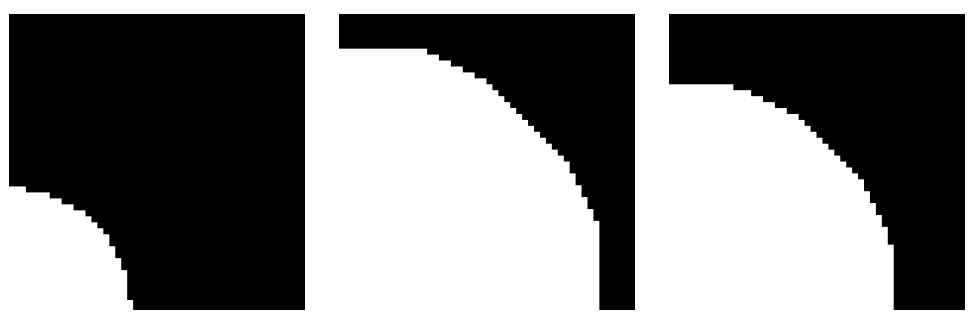

$\begin{array}{lll}\text { (a) } \beta=\gamma=0.00, \bar{t}= & \text { (b) } \beta=0.00, \gamma=1.00, & \text { (c) } \beta=0.50, \gamma=1.00, \\ 339 & \bar{t}=1606\end{array}$
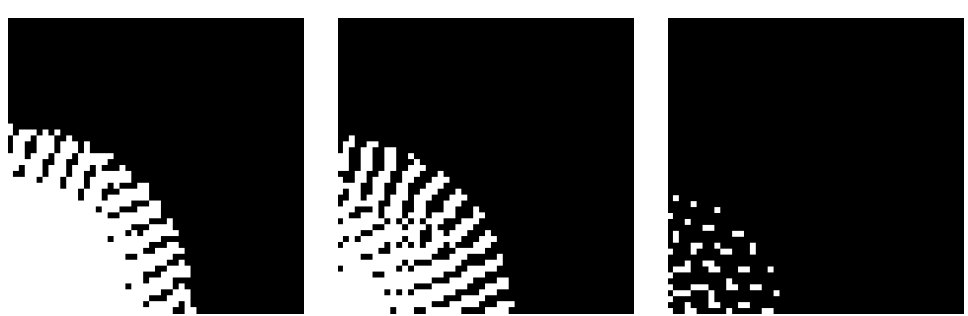

(d) $\beta=\gamma=1.00, \bar{t}=\quad$ (e) $\beta=1.25, \gamma=1.00, \quad$ (f) $\beta=1.00, \gamma=0.00$,

Figure 5: Long-run pattern archetypes according to changes in $\beta$ and $\gamma$ with $\widehat{f}=3.00$. 


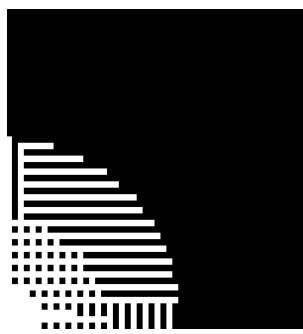

(a) $\widehat{f}=1.42$

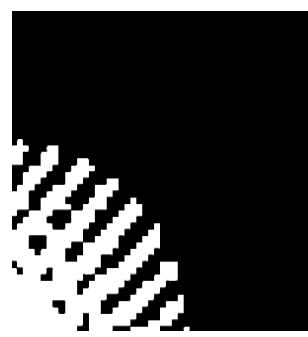

(d) $\widehat{f}=4.00$

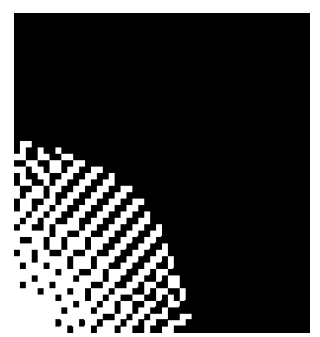

(b) $\widehat{f}=2.00$

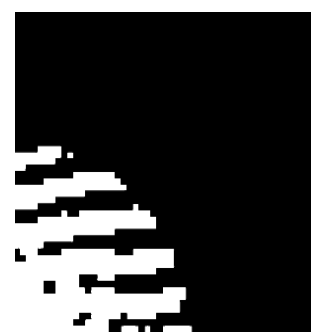

(e) $\widehat{f}=5.00$

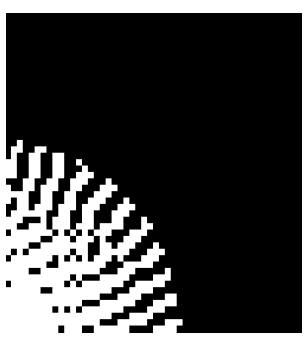

(c) $\widehat{f}=3.00$

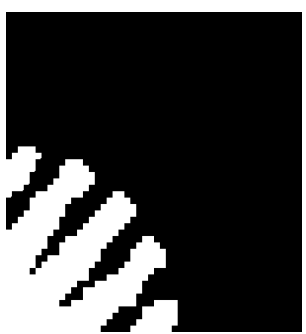

(f) $\widehat{f}=7.00$

Figure 6: Long-run pattern archetypes according to changes in neighbourhood size $\widehat{f}(\beta=1.25, \gamma=1.00)$. 